\title{
Su Sertliğinin ANFIS ile Tahmin Edilmesi: Köprüçay Örneği
}

\author{
*1 Tülay Suğra Küçükerdem and ${ }^{1}$ Kemal Saplıoğlu \\ ${ }^{*}$ Süleyman Demirel Üniversitesi Mühendislik Fakültesi İnşaat Mühendisliği Bölümü Isparta, Türkiye

\section{Özet}

Günümüzde şehirleşme ile sanayileşmenin hızla artması ve iklim değişikliklerine sebep olan küresel ısınma birtakım çevre sorunlarını da beraberinde getirmektedir. Su kalitesinin değişimi de önemli çevre sorunlarının başında gelmektedir. Su kalitesi suyun fiziksel, kimyasal ve biyolojik özellikleri hakkında fikir vermekte ve suyun kullanım amacına göre değerlendirilmektedir. Su kalitesini etkileyen önemli parametrelerden birisi de su sertliğidir.

Bu çalışmada suyun elektriksel iletkenlik özelliği, anyon veya katyon değerleri ve su miktarı ile farklı girdi kombinasyonları uygulanıp, su sertliğinin tahmini için Adaptif A $\breve{g}$ Tabanlı Bulanık Çıkarım Sistemi (ANFIS) kullanılarak birtakım modeller geliştirilmiştir.

Anahtar kelimeler: Su sertliği, su kalitesi modelleme, ANFIS modelleme

\begin{abstract}
Nowadays, urbanization and industrialization increase rapidly and global warming, which causes climate changes, brings with it some environmental problems. The change of water quality is one of the most important environmental problems. Water quality gives an idea about the physical, chemical and biological properties of the water and is evaluated according to the intended use of the water. One of the important parameters affecting water quality is water hardness.

In this study, different input combinations with water conductivity, anion or cation values and water amount are applied and some models have been developed bu using Adaptive Network Based Fuzzy Inference System to estimate water hardness.
\end{abstract}

Key words: Water hardness, water quality modeling, ANFIS modeling

\section{Introduction}

Özellikle son yıllarda sanayileşmenin ve küresel nüfusun artışı, nüfusla birlikte tarımsal tüketimin artması ve buna bağlı olarak sulama suyuna olan talebin çoğalması, suya olan ihtiyacımızı çok hızlı bir şekilde arttırmaktadır. Fakat bu hızlı artışı karşılayacak su kaynakları sınırlıdır. Suyun hidrolojik çevrim için önemli bir eleman olduğu düşünüldüğünde, mevcut su kaynaklarının tanınması, korunması ve geliştirilmesi önem kazanmaktadır. Su kaynaklarını tanımanın yollarından birisi de suların kalitesini tespit etmektir. Su kalitesinin tespiti; suyun fiziksel, kimyasal ve biyolojik karakterlerinin belirlenmesi ile mümkün olabilmektedir. Bu yüzden ülkemizde ve küresel çapta çok sayıda çalışma yapılmıştır. Bu çalışmaların bazıları veri toplayarak, deneysel şekilde ve zaman gerektirirken (Gedik ve arkadaşları [1], Kalyoncu ve diğerleri [2], Taş [3], Gültekin ve diğerleri [4], İleri ve arkadaşları [5], Cebe ve Barlas [6] ), bazıları teorik ve pratik (Yenilmez ve Aksoy [7], Tomas ve diğerleri [8], Zhang ve arkadaşları [9], Tekşen Ercan ve Anagün [10]) çalışmalardır. Deneysel çalışmalardan olan Gedik ve arkadaşları [1] Doğu Karadeniz Bölgesi'ndeki Rize ilinde bulunan Fırtına Deresi'nin su kalitesi özelliklerini belirleyip önceki çalışmalarla karşılaş̧ırmışlardır. Fırtına deresine ait 2 yıllık verilerle su sıcaklı̆̆ı, sudaki katı ve

*Corresponding author: Address: Faculty of Engineering, Department of Civil Engineering Suleyman Demirel University, 32260, Isparta TURKEY. E-mail address: kemalsaplioglu@sdu.edu.tr, Phone: +902462111213 
çözünmüş maddelerin su sertliği ile ilişkisini incelemişler; su sertliğinin kalsiyum, magnezyum gibi iyonlar ile ilişkili olduğunu gözlemlemişlerdir. Ayrıca Fırtına Deresi'nde daha önce yapılan çalışmalarla paralel sonuçlar elde etmişlerdir. Kalyoncu ve diğerleri [2] Aksu Çayı'ndaki su kalitesinin değişimini alg çeşitliliğine bağlı olarak incelemişlerdir ve su sertliğini etkileyen elektriksel iletkenlik ile alg çeşitliliği arasında yüksek düzeyde ilişki tespit etmişlerdir. Taş [3] Samsun'da Derbent baraj gölünden aldığı örneklerdeki su kalitesini; su sıcaklığı, çözünmüş oksijen, pH, elektriksel iletkenlik ve toplam sertliğin de içinde bulunduğu 16 parametre açısından inceleyip su sınıflarını belirlemiştir. Gültekin ve diğerleri [4] Trabzon ilindeki farklı havzaların su kalitelerinin hidrokimyasal özelliklerini belirlemiş ve Kıta İçi Su Kaynakları Kalite Kriterlerine göre havzaların su kalitelerini birçok parametre açısından yüksek kalitede olduğunu bulmuşlardır. İleri ve arkadaşları [5] Bursa Uluabat Gölü için sekiz noktadan alınan örneklerin su kalitesini fiziko-kimyasal analizlerle incelemişlerdir. Su kalitesini etkileyen parametrelerin sicaklık ve güneş 1şığının yoğunluğu gibi mevsimsel faktörlerle değiştiğini gözlemlemişlerdir.

Su kaynaklarının mevcut su kalitesini tanımanın yanında, gelecekteki su kalitelerini de bilmek, canlı yaşamını korumak ve ekonomik önlemler alınabilmesi açısından son derece önemlidir. Hidrolojik verilerin önceden kesin olarak bilinememesi her ne kadar hidrolojik çalışmaları zorlasa da bu zorluğu aşmak için birtakım tahmin modelleri geliştirilmiştir. Yenilmez ve Aksoy [7] Uluabat Gölü'nün su kalitesini WASP7.2 adı verilen bir benzetim modeli kullanarak, su kalitesinde önemli etkileri olan bazı parametreleri incelemişlerdir. Çalışma sonucunda model tahminleri ve gözlenen değerler arasında kabul edilebilir bir benzerlik bulmuşlardır. Tomas ve arkadaşları [8] Hırvatistan'ın Pannon bölgesindeki su kalitesinin değerlendirilmesi için çok değişkenli doğrusal regresyon modeli ve parçalı doğrusal regresyon modeli olmak üzere 6 değişkenli iki model oluşturmuşlardır. Çalışılan bölge için parçalı değişkenli doğrusal regresyon modelinin daha uygun olduğu sonucuna varmışlardır. Zhang ve diğerleri [9] Pekin'de mevcut çalışmalardan daha kapsamlı bir su kalitesi tahmin yöntemi geliştirmeyi amaçlamışlardır. Çalışmaları sonucunda parçacık sürü optimizasyonu tabanlı dalgacık sinir ağı yaklaşımı modelini önermişlerdir, model etkililiğini eldeki verilerle doğrulamışlardır. Tekşen Ercan ve Anagün [10], bulanık kural tabanlı uzman sistemin su kalitesini belirlemedeki yeterliliğini değerlendirmek için yapay sinir ağları ile kıyaslamasını çalışmışlardır. Çalışma sonucunda yapay sinir ağlarının oluşturulan bulanık kural tabanlı sisteme göre daha anlamlı sonuçlar çıkardığından bahsetmişlerdir.

Cebe ve Balas [6] HYDROTAM-3D alt modellerinden sayısal bir model kullanarak Kaş'ta 6 aylık gözlem verileri ile model sonuçlarını karşılaştırmışlardır. Rizo-Decelis [11] Meksika'da ölçülen su kalitesi verilerini istatistiksel yöntemleri de içeren farklı tahmin metotlarıyla belirlemişlerdir. Avila ve diğerleri [12] Yeni Zelanda Oreti Nehri için çoklu doğrusal regresyon, Markov zinciri, diskriminant analizi ve Bayes ağını da içeren birtakım istatistiksel analizlerle su kalitesini tahmin etmeye çalışmışlardır. Xu ve Liu [13] Çin'de su kalitesini belirlemek için dalgacık dönüşümünü yapay sinir ağıyla birleştiren bir matematik modelleme yöntemi sunmuşlardır. Abdelmalik [14] Mısır'da 18 farklı nokta için bir tür regresyon modeliyle su kalitesi parametrelerini modellemiştir. Slaughter ve arkadaşları [15] WQSAM isimli modeli geliştirmişlerdir. Ding ve arkadaşları [16] genetik algoritma ile bir çeşit yapay sinir ağını birleştirerek modelleme çalışmaları yapmışlardır. Jaddi ve Abdullah [17] yapay sinir ağlarını optimizasyon modelleriyle geliştirerek farklı bir model önermişlerdir.

Su kalitesi modellemede diğer çalışmaların yanı sıra Adaptif A ̆ Tabanlı Bulanık Çıkarım Sistemi (ANFIS) sıklıkla kullanılmıştır. Chen ve Liu [18] çalışmalarında multilineer regresyon, radyal tabanlı yapay sinir ağı ve ANFIS modeli kullanarak su kalitesini modellemişler, sonuçta ANFIS 
modelinin su kalitesi tahmininde uygun ve kabul edilebilir bir model olduğunu ifade etmişlerdir. Mousavi ve Amiri [19] İran'da yeraltı suyundaki nitrat konsantrasyonunu ANFIS modeli kullanarak tahmin etmeye çalışmışlardır. Gözlem kuyularından aldıkları ölçümler ile kurulan modellerin doğruluğunu karşılaştırmışlardır. Çalışmaları sonucunda nitrat konsantrasyonunun tahmininde modelin başarısını, yüksek korelasyona sahip parametrelerden seçilmesi ve girdi parametrelerinin sayısının artmasıyla ilişkilendirmişlerdir. Ahmed ve Shah [20] Bangladeş Surma Nehri'nde biyokimyasal oksijen ihtiyacını belirlemek için iki tür ANFIS yapısı oluşturmuşlar, çalışma sonucunda biyokimyasal oksijen ihtiyacını uyarlamalı sinirsel bulanık çıkarım sistemi ile doğrulayabildiklerini ve ANFIS yapısının nehir suyu kalitesi tahmininde kullanılabilir bir araç olduğunu belirtmişlerdir. Sahoo ve diğerleri [21] Hindistan'da Brahmani Nehri su kalitesinin tahmini için 4 giriş parametresi ile ANFIS modeli kurarak sonuçları derecelendirmişlerdir. Modelde öngörülen verilerin gerçek verilerle uyumlu olduğu belirtilmiştir.

\section{Materials and Method}

\section{1. Çalışma Alanı ve Veriler}

Bu çalışmadaki modeller Köprüçay nehri , 902 nolu Beşkonak akım ölçüm istasyonundan alınan 1995-2002 su yılı verileri yardımıyla kurulmuştur. Doğusundan Kocadere kolu, batısından ise Sağırin kolunun akıma katıldığı, Serik düzlüğü boyunca devam eden ve Akdeniz'e dökülen Köprüçay Nehri, Anamas dağının batı eteğinde bulunan Oluk ve Köprü membalarından doğmaktadır. Havzasına bağlanan kollar haricinde $156 \mathrm{~km}$ uzunluğunda olan nehir $2498 \mathrm{~km}^{2}$ lik bir yağış toplama alanına, yıllık ortalama $3,2 \times 10^{9} \mathrm{~m}^{3}$ akışa sahip olan bu nehir bölgenin en önemli nehirleri arasındadir.

902 nolu Beşkonak akım gözlem istasyonu, Antalya Serik havzasının 36 km kuzeyinde Köprüçay Nehri üzerinde 37,141 kuzey enlemi ve 31,187 doğu boylamındadır . Yaklaşık olarak yağış alanı $2072,8 \mathrm{~km}^{2}$ olan bu istasyonun deniz seviyesinden yüksekliği ise $95 \mathrm{~m}$ dir.

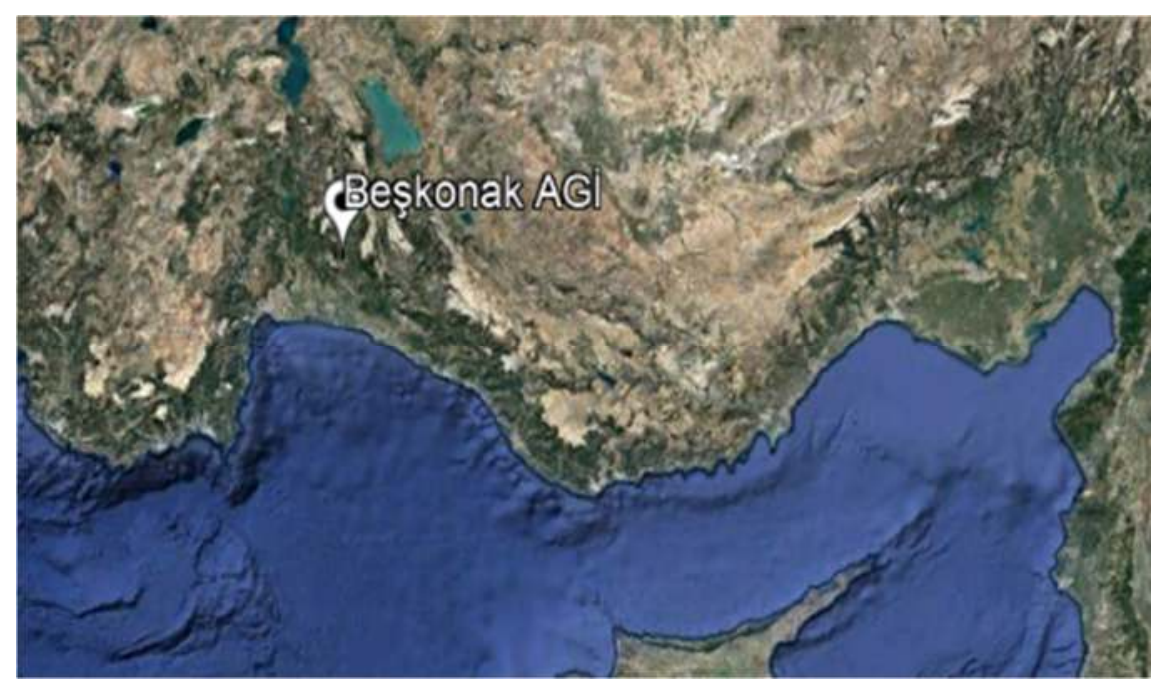

Şekil 1. Kullanılan verilerin alındığ istasyon konumu 
Çalışmada kullanılan verilerin basit istatistiksel analizleri Tablo 1'de verilmiştir.

Tablo 1. Kullanılan Verilere Ait Temel İstatistiksel Bilgiler

\begin{tabular}{|c|c|c|c|c|c|c|}
\hline MEVSİMLER & & $\begin{array}{c}\text { VERI } \\
\text { SAYISI }\end{array}$ & MİNiMUM & MAKSİMUM & $O R T A L A M A$ & S.SAPMA \\
\hline \multirow{4}{*}{$S O N B A H A R$} & $\begin{array}{l}\text { ELEKTRİKSEL } \\
\text { ILETKENLIK }\end{array}$ & 24 & 269,00 & 460,00 & 321,79 & 50,27 \\
\hline & $\begin{array}{l}\text { ANYONLAR - } \\
\text { KATYONLAR }\end{array}$ & 24 & 2,84 & 5,19 & 3,58 & 0,59 \\
\hline & SU MİKTARI & 24 & 32,37 & 390,52 & 54,04 & 72,01 \\
\hline & SU SERTLİĞİ & 24 & 13,10 & 24,50 & 16,43 & 2,94 \\
\hline \multirow{4}{*}{ KISS } & $\begin{array}{l}\text { ELEKTRİKSEL } \\
\text { İLETKENLIK }\end{array}$ & 24 & 220,00 & 387,00 & 287,75 & 50,08 \\
\hline & $\begin{array}{l}\text { ANYONLAR - } \\
\text { KATYONLAR }\end{array}$ & 24 & 2,31 & 4,41 & 3,07 & 0,59 \\
\hline & SU MİKTARI & 24 & 35,33 & 793,58 & 175,55 & 196,30 \\
\hline & SU SERTLİĞİ & 24 & 10,40 & 21,00 & 14,56 & 3,02 \\
\hline \multirow{4}{*}{$\dot{I L K B} A H A R$} & $\begin{array}{l}\text { ELEKTRİKSEL } \\
\text { ILLETKENLIKK }\end{array}$ & 24 & 190,00 & 365,00 & 267,92 & 54,80 \\
\hline & $\begin{array}{l}\text { ANYONLAR - } \\
\text { KATYONLAR }\end{array}$ & 24 & 1,98 & 4,10 & 2,90 & 0,60 \\
\hline & SU MİKTARI & 24 & 56,31 & 249,11 & 106,95 & 38,95 \\
\hline & SU SERTLİĞİ & 24 & 9,00 & 19,50 & 13,53 & 3,01 \\
\hline \multirow{4}{*}{$Y A Z$} & $\begin{array}{l}\text { ELEKTRİKSEL } \\
\text { İLETKENLIK }\end{array}$ & 24 & 220,00 & 453,00 & 289,59 & 69,07 \\
\hline & $\begin{array}{l}\text { ANYONLAR - } \\
\text { KATYONLAR }\end{array}$ & 24 & 2,36 & 5,15 & 3,18 & 0,79 \\
\hline & SU MÍKTARI & 24 & 36,21 & 76,16 & 51,07 & 11,85 \\
\hline & SU SERTLİĞİ & 24 & 11,20 & 24,50 & 14,68 & 3,83 \\
\hline
\end{tabular}

\subsection{Adaptif Ăg Tabanlı Bulanık Çıkarım Sistemi (ANFIS)}

Bulanık mantık 1965 yılında Zadeh tarafından tanımlanmış temeli küme ve alt küme kavramlarına dayanan bir metottur. Girdi değişkenleri ile çıktı değişkenleri arasında bulanık kümeleri kullanarak ilişki kuran bulanık sistemler, sayısal karşılığı bulunmayan değişkenleri dahi, uzman kişiler yardımıyla modelleyebilmektedir. Bulanık sistemlerde çok sayıda farklı modeller bulunmaktadır. 
Sugeno tipi modellerde, girdi ve çıktı veri setlerine göre bulanık kurallar oluşturulmasına imkan sağlar. Diğer sistemlere göre parametrelerin optimizasyonu daha kolaydır. Bu tip modellerde çıktı parametresi girdi değişkenlerinin üyelik fonksiyonlarına sahiptir. Parametreleri optimize edilen Sugeno tipi çıkarım sistemlerine Yapay Sinir Ağı Tabanlı Bulanık Çıkarım Sistemi (ANFIS) adı verilir .

ANFIS parametrelerinin optimizasyonunda, geriye yayma, en küçük kareler kestirimi, Kalman filtresi ya da birden fazla matematiksel optimizasyon yönteminin birleşmesinden oluşan hibrid öğrenme algoritmaları gibi değişik yöntemler kullanılabilir . Sugeno tipi bulanık çıkarım sistemlerinde kurallar;

Eğer $\mathrm{x} \in A$ ve $\mathrm{y} \in \mathrm{B}$ ise $\mathrm{f}=\mathrm{f}(\mathrm{x}, \mathrm{y})$ şeklindedir.

Burada A ve B sırasıyla öncül kısımdaki $X$ ve $Y$ değişken uzayını bulanık alt uzaylara ayıran kümelerin etiketidir. f ise o kurala ait çıkış değeridir ve bu, girdi değişkenlerinin bir fonksiyonudur. Herhangi bir x,y girdi çifti için sonuç çıkış değeri f ise tüm kuralların çıkış değeri f' 'lerin ağırlıklı ortalamasidir.

\section{Değerlendirmeler}

Çalışmamızda ANFIS yardımıyla elektriksel iletkenlik, anyonlar ve katyonlar, su miktarı gibi parametreler girdi değişkenleri olarak kullanılmış ve su sertliği tahmin modelleri geliştirilmeye çalışılmıştır. Parametrelerin tek başlarına, ikili kombinasyonları ve üçünün birlikte girdi olarak verilmesi ile çeşitli modeller oluşturulmuşlardır. Ayrıca oluşturulan modeller parametrelerin farklı küme sayılarına bölünmesine bağlı olarak çeşitlendirilmiştir. Modeller oluşturulurken eldeki verilerin \% 80 'i eğitim \%20 'si ise test için ayrılmıştır. Eğitim aşamasında hiçbir şekilde test verileri modele tanıtılmamıştır. Test verileri sadece model oluşturulduktan sonra öğrenmenin ezber olup olmadığını test etmek için kullanılmıştır. Tablo 2'de elde edilen tüm eğitim ve test sonuçlarının regresyon değerleri ve hataları özetlenmiştir. Sonuçlarda anyon ve katyon değerlerinin kullanıldığı modellerin diğerlerine oranla daha iyi sonuçlar verdiği gözlemlenmiştir. Anyon ve katyon girdilerine ek olarak diğer parametrelerin de kullanıldığı modeller hatayı binde bir oranında azaltmıştır. Bu nedenle modellerde girdi parametresi olarak anyon ve katyon değerlerinin kullanılması yeterli olabilecektir. 
Tablo 2. Model Sonuçları ve Sonuçlara Ait Hata Değerleri

\begin{tabular}{|c|c|c|c|c|c|}
\hline \multirow[t]{2}{*}{ Alt Küme } & \multirow[t]{2}{*}{ Girdiler } & \multicolumn{2}{|c|}{ Eğitim } & \multicolumn{2}{|c|}{ Test } \\
\hline & & $\mathbf{R}^{2}$ & $\begin{array}{l}\text { MUTLAK } \\
\text { HATA }\end{array}$ & $\mathbf{R}^{2}$ & $\begin{array}{c}\text { MUTLAK } \\
\text { HATA }\end{array}$ \\
\hline $7-7-7$ & \multirow{11}{*}{$\mathbf{E} \dot{\mathbf{I}}+\mathbf{A K}+\mathbf{S M}$} & 0,999 & 0,004 & 0,779 & 0,018 \\
\hline $6-6-6$ & & 0,999 & 0,004 & 0,833 & 0,064 \\
\hline $5-5-5$ & & 0,999 & 0,005 & 0,983 & 0,024 \\
\hline $4-4-4$ & & 0,998 & 0,008 & 0,994 & 0,017 \\
\hline $3-3-3$ & & 0,998 & 0,008 & 0,989 & 0,020 \\
\hline $2-2-2$ & & 0,990 & 0,017 & 0,994 & 0,013 \\
\hline $4-5-4$ & & 0,999 & 0,007 & 0,993 & 0,018 \\
\hline $4-4-5$ & & 0,999 & 0,007 & 0,989 & 0,022 \\
\hline $3-4-3$ & & 0,998 & 0,008 & 0,993 & 0,017 \\
\hline $4-3-3$ & & 0,998 & 0,008 & 0,993 & 0,017 \\
\hline $3-3-4$ & & 0,997 & 0,009 & 0,990 & 0,018 \\
\hline $5-5$ & \multirow{4}{*}{$\mathbf{E} \dot{\mathbf{I}}+\mathbf{A K}$} & 0,995 & 0,012 & 0,992 & 0,038 \\
\hline $4-4$ & & 0,995 & 0,012 & 0,994 & 0,015 \\
\hline $3-3$ & & 0,993 & 0,015 & 0,993 & 0,014 \\
\hline $2-2$ & & 0,977 & 0,022 & 0,991 & 0,018 \\
\hline $5-5$ & \multirow{4}{*}{$\mathbf{E} \dot{I}+\mathbf{S M}$} & 0,972 & 0,026 & 0,932 & 0,046 \\
\hline $4-4$ & & 0,972 & 0,027 & 0,962 & 0,038 \\
\hline $3-3$ & & 0,969 & 0,027 & 0,957 & 0,038 \\
\hline $2-2$ & & 0,966 & 0,031 & 0,972 & 0,029 \\
\hline 5 & \multirow{3}{*}{$\mathbf{A K}+\mathbf{S M}$} & 0,998 & 0,007 & 0,993 & 0,017 \\
\hline 4 & & 0,997 & 0,009 & 0,994 & 0,016 \\
\hline 3 & & 0,979 & 0,019 & 0,989 & 0,018 \\
\hline 5 & \multirow{4}{*}{$\mathbf{E I}$} & 0,972 & 0,028 & 0,964 & 0,019 \\
\hline 4 & & 0,974 & 0,027 & 0,957 & 0,039 \\
\hline 3 & & 0,971 & 0,029 & 0,969 & 0,033 \\
\hline 2 & & 0,970 & 0,030 & 0,977 & 0,027 \\
\hline 5 & \multirow{4}{*}{ AK } & 0,963 & 0,022 & 0,993 & 0,018 \\
\hline 4 & & 0,962 & 0,021 & 0,992 & 0,021 \\
\hline 3 & & 0,961 & 0,020 & 0,991 & 0,020 \\
\hline 2 & & 0,960 & 0,021 & 0,993 & 0,019 \\
\hline
\end{tabular}

Eİ: Elektriksel İletkenlik AK: Anyonlar ve Katyonlar SM: Su Miktarı 

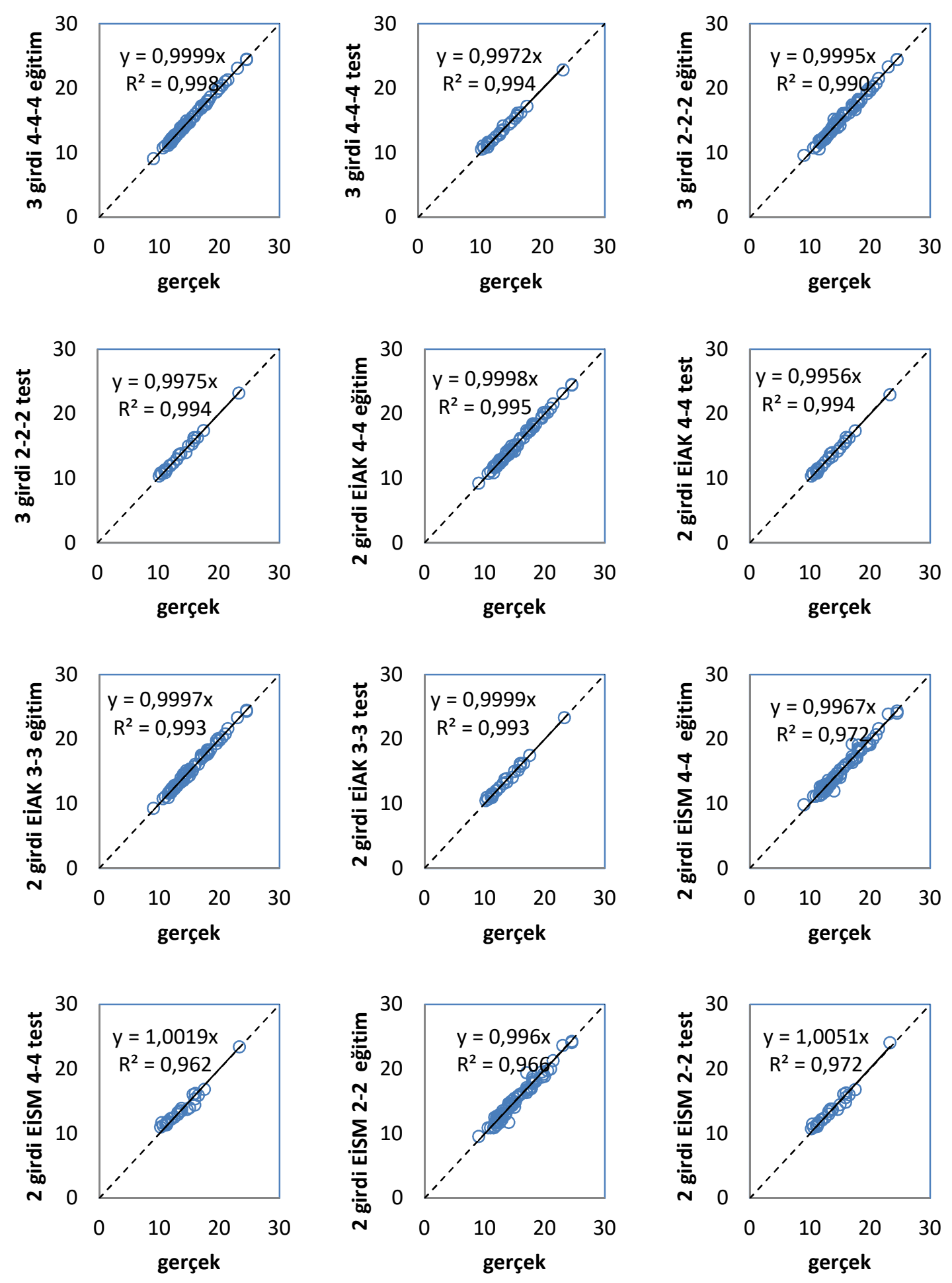

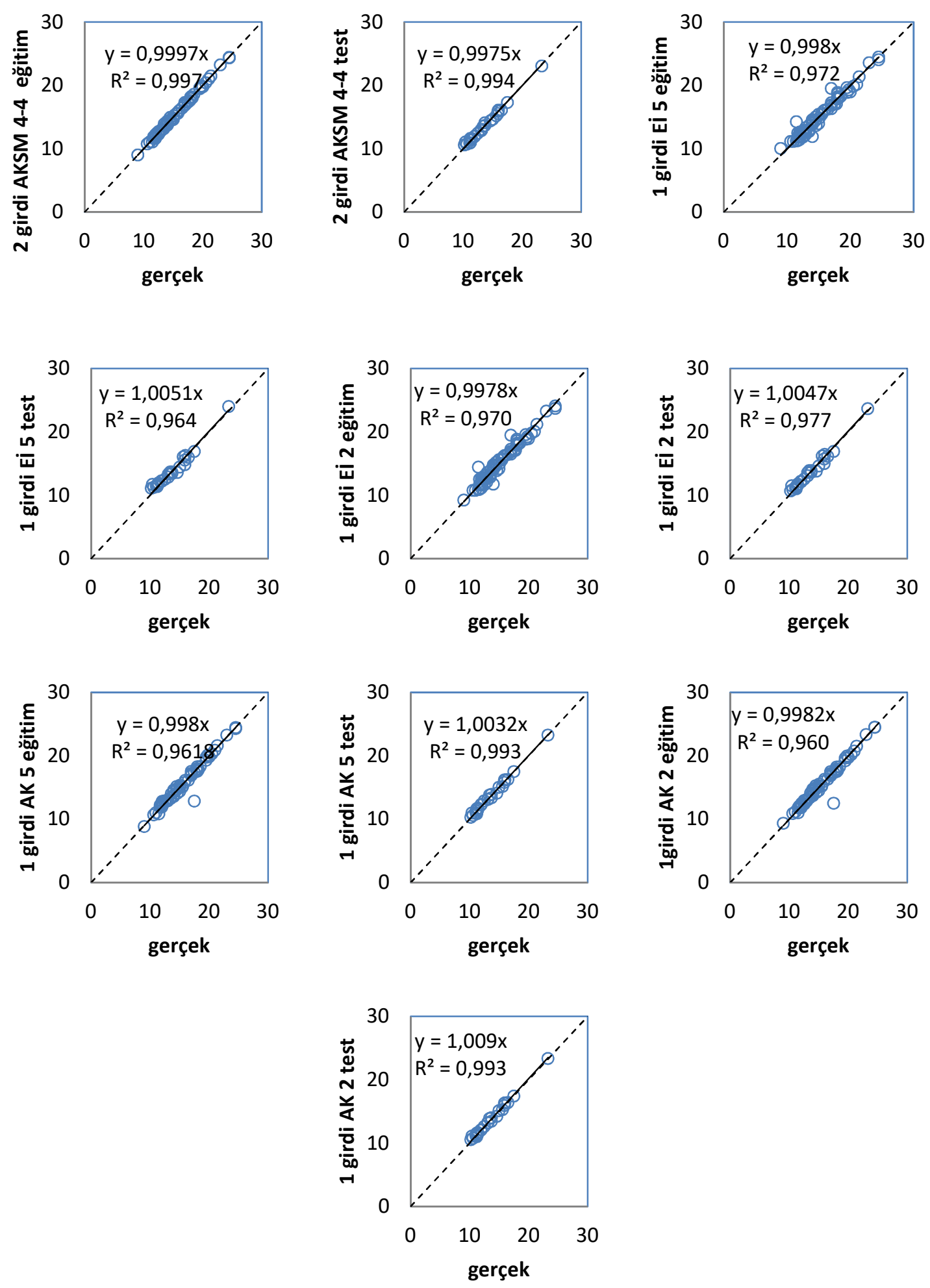

Şekil 2. Oluşturulan modellerin eğitim ve test sonuçları 


\section{Sonuçlar}

Çalışmamızda Köprüçay nehri 902 nolu istasyondan alınan veriler kullanılmış ve ANFIS yardımıyla bu istasyona ait su sertliği değerleri tahmin edilmeye çalışılmıştır. Su sertliğini tahmin etmek için anyon-katyon değerleri ve elektriksel iletkenliğin yanısıra su miktarının etkisi de incelenmiştir. Oluşturulan modellemeler bu girdilerin farklı kombinasyonlarının yanı sıra alt küme sayılarının değiştirilmesi ile elde edilmiştir. Modellemeler sonucunda anyon ve katyonların su sertliği tahmininde yaklaşık \% 2 hata payı ile doğruya yakın sonuçlar verdiği görülmüştür. Elektrik iletkenliği ve su miktarının girdi olarak kullanıldığı modellerdeki hata oranının \% 4 lere yakın olduğu görülmüştür. Tüm parametrelerin birlikte kullanıldığı modellerde ise sadece anyon ve katyon değerlerinin kullanıldığı modellere göre yaklaşık binde bir daha sağlıklı sonuçlar verdiği görülmüştür. Gelecekteki çalışmalarda girdi parametreleri zenginleştirilip veri sayısı arttırılarak hata oranı daha düşük modellerin kurulabileceği öngörülmüştür.

\section{Kaynaklar}

[1] Gedik K, Verep B, Terzi E, Fevzioğlu S. Fırtına deresi (Rize)'nin fiziko-kimyasal açıdan su kalitesinin belirlenmesi. Ekoloji Dergisi 2010; 19(76); 25-35.

[2] Kalyoncu H, Barlas M, Yorulmaz B. Aksu Çayı'nda (Isparta-Antalya) epilitik alg çeşitliliği ve akarsuyun fizikokimyasal yapısı arasındaki ilişki. Ekoloji Dergisi 2008; 17(66);15-22.

[3] Taş B. Derbent Baraj Gölü (Samsun) su kalitesinin incelenmesi. Ekoloji Dergisi 2006; 15(61); 6-15.

[4] Gültekin F, Ersoy A F, Hatipoğlu E, Celep S. Trabzon ili akarsularının yağışlı dönem su kalitesi parametrelerinin belirlenmesi. Ekoloji Dergisi 2012; 21(82); 77-88.

[5] İleri S, Karaer F, Katip A, Onur S. Sı̆̆ göllerde su kalitesi değerlendirmesi, Uluabat Gölü örneği. Uludağ Üniversitesi Mühendislik-Mimarlık Fakültesi Dergisi 2014; 19(1); 47-57.

[6] Cebe K, Barlas L. Water quality modelling in Kaş bay. Applied Mathematical Modelling 2016; 40; 1887-1913.

[7] Yenilmez F, Aksoy A. Uluabat Gölü su kalitesinin WASP7.2 modeli kullanılarak değerlendirilmesi. İzmir, 2007.

[8] Tomas D, Curlin M, Maric A S. Assessing the surface water status in Pannonian ecoregion by the water quality index model, Ecological Indicators 2017; 79; 182-190.

[9] Zhang L, Zou Z, Shan W. Development of a method for comprehensive water quality forecasting and its application in Miyun reservoir of Beijing, China. Journal of Environmental Sciences 2016; 56.

[10] Ercan Tekşen H, Anagün A S. Su kalitesi indeksinin belirlenmesinde uzman bulanık sistem yaklaşımı. Antalya, 2016. 
[11] Rizo-Decelis L D, Pardo-Igúzquiza E, Andreo B. Spatial prediction of water quality variables along a main river channel, in presence of pollution hotspots. Science of the Total Environment 2017; 605(606); 276-290.

[12] Avila R, Horn B, Moriarty E, Hodson R, Moltchanova E. Evaluating statistical model performance in water quality prediction. Journal of Environmental Management 2018; 206; 910-919.

[13] Xu L, Liu S. Study of short-term water quality prediction model based on wavelet neural network. Mathematical and Computer Modelling 2013; 58; 807-813.

[14] Abdelmalik K. Role of statistical remote sensing for Inland water quality parameters prediction. The Egyptian Journal of Remote Sensing and Space Sciences 2016.

[15] Slaughter A, Hughes D, Retief D H, Mantel S K. A management-oriented water quality model for data scarce catchments. Environmental Modelling \& Software 2017; 97; 93-111.

[16] Ding Y R, Cai Y J, Sun P D, Chen B. The use of combined neural networks and genetic algorithms for prediction of river water quality. Journal of Applied Research and Technology 2014; $12 ; 493-499$.

[17] Jaddi N S ve Abdullah S. A cooperative-competitive master-slave global-best harmony search for ANN optimization and water-quality prediction. Applied Soft Computing 2017; 51; 209224.

[18] Chen W B, Liu W C. Water quality modeling in reservoirs using multivariate linear regression and two neural network models. Hindawi 2015.

[19] Mousavi S F, Amiri M J. Modelling nitrate concentration of groundwater using adaptive neural-based fuzzy inference system. Soil\&Water Res 2012; 7; 73-83.

[20] Ahmed M A, Shah S M A. Application of adaptive neuro-fuzzy inference system (ANFIS) to estimate the biochemical oxygen demand (BOD) of Surma River. Journal Of King Saud University-Engineering Sciences 2017; 29;237-243.

[21] Sahoo M M, Patra K, Khatua K. Inference of water quality index using ANFIS and PCA. Aquatic Procedia 2015; 4;1099-1106. 